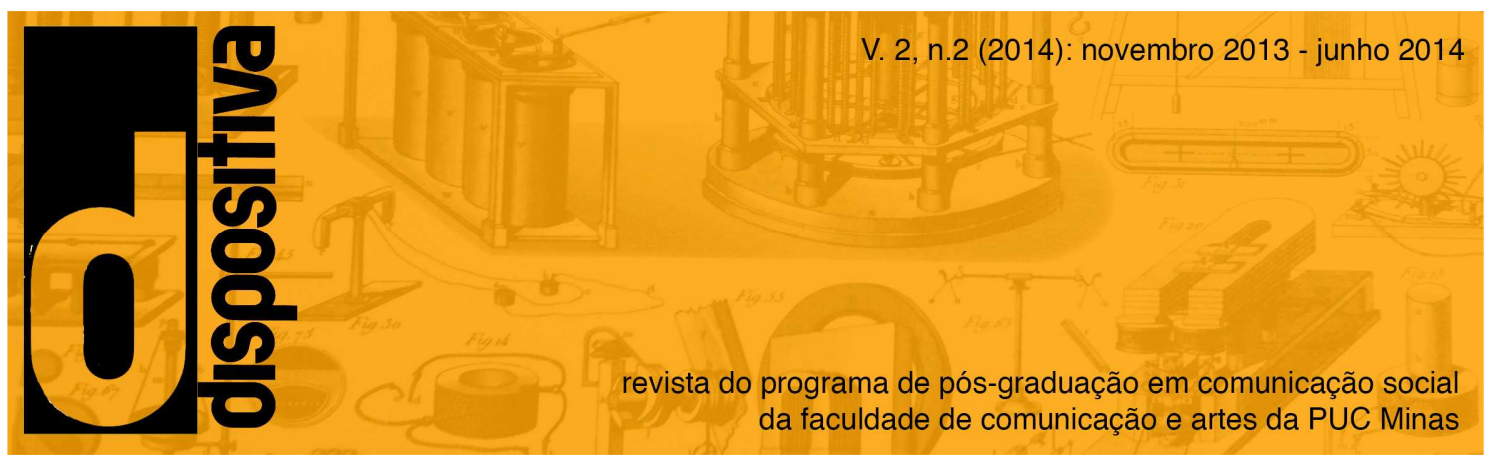

\title{
COMUNICAÇÃO E GESTÃO ORGANIZACIONAL EM TEMPOS DE VIGILÂNCIA E CONTROLE: DO PANÓPTICO AO BINÓCULO
}

\author{
COMMUNICATION AND ORGANIZATIONAL MANAGEMENT IN TIMES \\ OF SURVEILLANCE AND CONTROL: FROM THE PANOPTICON TO THE BINOCULARS \\ Marcelo da Silva ${ }^{1}$ \\ Mônica Aparecida de Castro ${ }^{2}$
}

\begin{abstract}
Resumo: Este artigo aborda a relação da comunicação interna com o imaginário e a cultura das organizações, tendo como objetivo discutir a influência da cultura brasileira no ambiente organizacional e nos estilos de gestão que têm sido levados a cabo por diferentes organizações. Buscamos assim, uma reflexão sobre a necessidade da comunicação interna desvendar e transformar o imaginário e a cultura das organizações para a construção de melhores ambientes de trabalho, mais diálogo e equilíbrio entre a ética $e$ a estética do discurso institucional/mercadológico, eivado de uma série de eufemismos que servem para escamotear os sistemas de vigilância e controle, "romantizando" as práticas que permeiam sua cotidianidade, apagando as contradições próprias da sociedade $e$ organizações contemporâneas.
\end{abstract}

Palavras-chave: Comunicação interna. Discurso. Identidade. Vigilância.

\begin{abstract}
This article is about the relationship of internal communication with the imaginary and the culture of organizations in order to discuss the influence of the Brazilian culture in organizational environment and the management styles in different organizations. Therefore, we intend, fetching a reflection on the need for internal communication, to unveil and transform the imaginary and the culture of organizations in order to build better work environments, improve communication and balance between ethics and the institutional/marketing discourse templates, which are fraught with a lot of euphemism that serves to conceal the surveillance and control systems, "romanticizing" the practices that permeate the daily lives, erasing the contradictions of contemporary society and organizations.
\end{abstract}

Keywords: Internal communication. Discourse. Identity. Surveillance.

\footnotetext{
${ }^{1}$ Doutorando em Comunicação Social pela Universidade Metodista de São Paulo. Professor do curso de Relações Públicas da Universidade Federal do Maranhão, bolsista Taxa-Capes. E-mail: marcelosilva_rp@hotmail.com.

${ }^{2}$ Mestrado em Comunicação Social pela Universidade Metodista de São Paulo - UMESP, em São Bernardo do Campo, SP. E-mail: monicacastro@uol.com.br.
} 


\section{Introdução}

A cultura das organizações ${ }^{3}$ e a sua relação com a comunicação organizacional tem sido cada vez mais, tema de pesquisas e de estudos com vistas a evoluir em práticas gerenciais e em melhoria de todos os processos inerentes a todas organizações.

Nas pesquisas a respeito da comunicação organizacional, a cultura das empresas é um tema muito presente e vários autores reiteram a importância da comunicação no papel de construir, implementar, reforçar e transformar a cultura de uma organização e suas práticas cotidianas.

A necessidade de se adequar a uma nova realidade social, política e econômica, exige das organizações brasileiras investimentos e melhorias nos seus processos de gestão e no relacionamento com os seus diversos públicos. A importância do público essencial de sustentação - funcionário - tem crescido neste novo cenário. Engajar os empregados com os negócios e as práticas da empresa, e fazê-lo sentir-se participante de todo o processo organizacional, tem sido meta e bússola de muitas organizações. No entanto, muitas dificuldades impedem que alcancem resultados positivos, tais como: a baixa motivação para o trabalho, problemas no clima organizacional, alto índice de absenteísmo, baixa produtividade e problemas de assédio moral.

Tais dificuldades inserem-se em um contexto de competitividade que leva as organizações a adotarem posicionamentos agressivos frente à perda de espaço no mercado e à dificuldade de "formar", informar e reter capital humano; muitos são os estratagemas levados a efeito pelas organizações com o intuito de envolver seus funcionários no alcance de metas e objetivos; todavia, muitas práticas ficam mais no plano da vigilância e do controle, amiúde materializadas em forma de eufemismos que assassinam a subjetividade do sujeito.

\footnotetext{
${ }^{3}$ Neste artigo utilizamos os termos organizações, instituições e empresas como sinônimos, já que nossa preocupação não reside em debater essas nomenclaturas nem tampouco seu universo conceitual.
} 


\section{Organizações, cultura e desenvolvimento}

Os imperativos da sociedade de consumo e o avanço das tecnologias e das redes sociais virtuais têm exigido das organizações novas posturas diante dos cenários que despontam. Nesse sentido, Vasconcellos (1995) diz que "[...] no momento em que envidamos enorme esforço coletivo para vencermos um quadro de apatia e subdesenvolvimento, é fundamental que pensemos os obstáculos que foram historicamente colocados ao desejo modernizante". (VASCONCELLOS, 1995, p. 220).

O autor assevera que os obstáculos que impedem o desenvolvimento das organizações podem ser construídos dentro dela mesma, e que há outros que estão arraigados à cultura brasileira, povoando as ambiências como um todo, haja vista que modernizar as empresas implica em reconhecer estes obstáculos, trabalhar nas fragilidades e formular novos cenários.

Conhecer a cultura organizacional é conhecer também os fatores que dificultam o avanço das organizações e que trazem muitos danos para o relacionamento entre gestores e empregados. Conhecendo-se tais obstáculos, é preciso adotar medidas para superá-los e a comunicação organizacional apresenta-se como importante protagonista neste trabalho de mudança de postura por meio da sensibilização e da tomada de consciência.

O temário que perpassa as discussões acerca da cultura organizacional vem sendo estudado com mais profundidade desde a década de 1970, já que há um caleidoscópio de conceitos de cultura organizacional apresentados por diferentes autores. Freitas (2002) defende duas compreensões a respeito: a primeira é que a cultura organizacional é um instrumento de poder. A segunda, que a cultura organizacional é um:

conjunto de representações imaginárias sociais que se constroem e reconstroem nas relações cotidianas dentro da organização e que se expressam em termos de valores, normas, significados e interpretações, visando um sentido de direção e unidade, tornando a organização fonte de identidade e de reconhecimento para seus membros. (FREITAS, 2002, p. 97).

A cultura organizacional pode ser investigada de várias maneiras. Uma delas é por meio dos estudos da cultura nacional. Alguns autores relacionam certos "personagens" que foram marcantes na história das civilizações, com vários estilos 
gerenciais praticados ainda hoje em muitas organizações brasileiras para compreender os modelos de gestão e administração que imperam no Brasil.

Outra maneira é identificar quais imaginários estão relacionados com o dia a dia das organizações, ou seja, qual é o imaginário relacionado à prática do trabalho que vigora na organização, e qual a imagem do gerente ou do chefe que predomina na visão dos empregados.

Motta (1995) apresenta métodos para conhecermos o imaginário e a cultura de uma organização.

\begin{abstract}
Existem muitas formas de penetrar ou resgatar a cultura de uma organização. A análise das histórias ou da história, a interpretação dos costumes, dos ritos, dos rituais, das cerimônias, dos valores, dos mitos são alguns dos caminhos. [...] Um caminho especialmente interessante é o estudo das culturas organizacionais a partir de traços das culturas nacionais. (MOTTA, 1995, p. 196).
\end{abstract}

Freitas (2002) também relaciona imaginário e cultura, afirmando que "[...] a cultura organizacional desenvolvida nas grandes empresas é o veículo de um imaginário que as legitima como a principal fonte fornecedora de identidade para os indivíduos que nela trabalham" (FREITAS, 2002, p. 11). Fato que confirma a necessidade de se investir na comunicação organizacional integrada, já que responsável pela construção dialógica da identidade corporativa e pela verificação de sua viabilidade nas práxis organizacionais.

Dessa forma, compreendemos que o imaginário que cada pessoa traz para o ambiente de trabalho deve participar da formação da cultura da empresa que, por sua vez, alimenta (ou modifica) o imaginário. Assim, questões do imaginário e da cultura organizacional podem representar agentes de desenvolvimento ou de obstáculos para melhorias no desempenho geral das organizações, na consecução de suas práticas, nas relações interpessoais e na construção da cotidianidade organizacional.

A primeira ação para se conhecer o imaginário e a cultura de uma empresa, é analisar em que espaço geográfico e cultural ela está inserta. Motta (1995) afirma que

\footnotetext{
para entender as organizações em países diferentes é necessário entender suas culturas nacionais, e entender as concepções de vida em sociedade que marcam essas culturas, bem como as formas de governo dos homens, igualmente enquanto concepções. (MOTTA, 1995, p. 191).
}

A cultura nacional gerou alguns estilos de gestão nas organizações. Alguns deles podem ainda ser vistos em proporções diferenciadas. O imaginário é elemento de 
construção das culturas nacionais e, assim, consequentemente, das organizações. 0 imaginário está diretamente relacionado à cultura. As culturas constroem o imaginário, assim como o imaginário também constrói as culturas. Essa é uma perspectiva ao mesmo tempo dialógica e dialética, já que compreende um processo no qual múltiplos atores interagem de modo aberto e sinérgico.

É através da comunicação que o imaginário - formador da cultura organizacional - é distribuído, construído, modificado e novamente colocado em circulação no ambiente organizacional, como esclarece Baldissera (2010).

\footnotetext{
Complexus ${ }^{4}$ de diálogos e significação, permanentemente (re) tecidos pelos diferentes sujeitos - seus imaginários e suas subjetividades - as organizações são/ estão tensionadas ao entorno sociocultural, perturbandoo e sendo perturbadas por ele. (BALDISSERA, 2010, p. 61).
}

As pessoas entram nas organizações sem conhecer o imaginário que prevalece e os demais componentes que formam a cultura local. A comunicação é agente modificador desta situação de desconhecimento e também pode engendrar formas tácitas de aceitação de certos imperativos que campeiam o imaginário organizacional, produzindo controle em detrimento de diálogo e compreensão mútua na pluralidade.

\subsection{O imaginário do trabalho nas organizações}

Para compreendermos como um empregado se relaciona com o seu trabalho, é fulcral conhecermos as possíveis imagens que são construídas na relação entre o sujeito do trabalho e a palavra trabalho.

É comum relacionarmos o trabalho com sofrimento, dor, labuta, luta. Segundo Baldissera (2010), "além do trabalho ser um castigo divino expresso na sentença 'ganharás o pão com o suor do teu próprio trabalho', o sofrimento vinculado ao trabalho representa uma forma de purificação, de reconciliação com Deus, de redenção" (BALDISSERA, 2010, p. 65).

Compreendemos com mais profundidade esta relação do trabalho com a dor, quando procuramos a origem da palavra, a qual segundo Albornoz (1986):

\footnotetext{
${ }^{4}$ Complexus significa “o que é tecido em conjunto”. (MORIN, 2001, p. 20 apud BALDISSERA, 2010, p. 61).
} 
a palavra trabalho se origina do latim tripalium, [...] Tripalium era um instrumento feito de três paus aguçados, algumas vezes ainda munidos de pontas de ferro [...] tripalium apenas como instrumento de tortura [...]. A tripalium se liga o verbo do latim vulgar, que significa justamente torturar (ALBORNOZ, 1986 apud BATISTTI; BAVARESCO, 2010, p.10).

As figuras 1 e 2 - apresentadas abaixo - denotam expressões do tripalium dentro de uma concepção que transcende a descrição do dicionário.

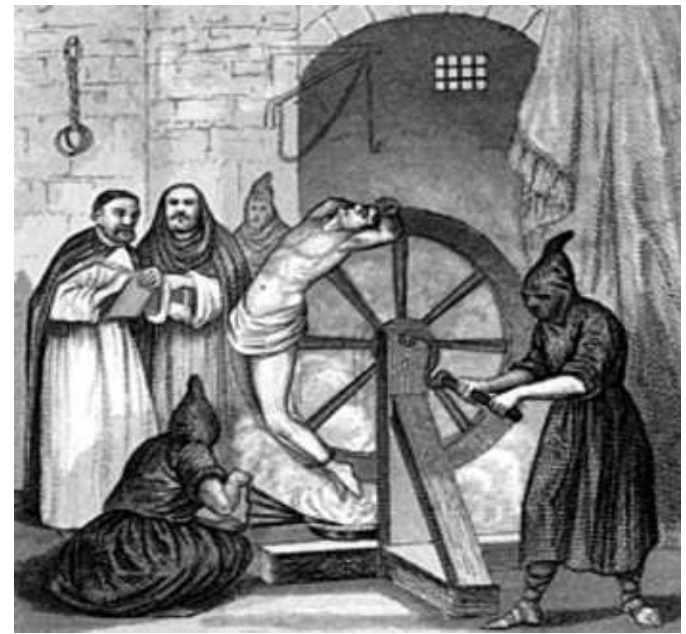

Figura 1. 475 x 494 - http://4.bp.blogspot.com//tripalium.jpg Fonte: Imagens de tripalium (2013)

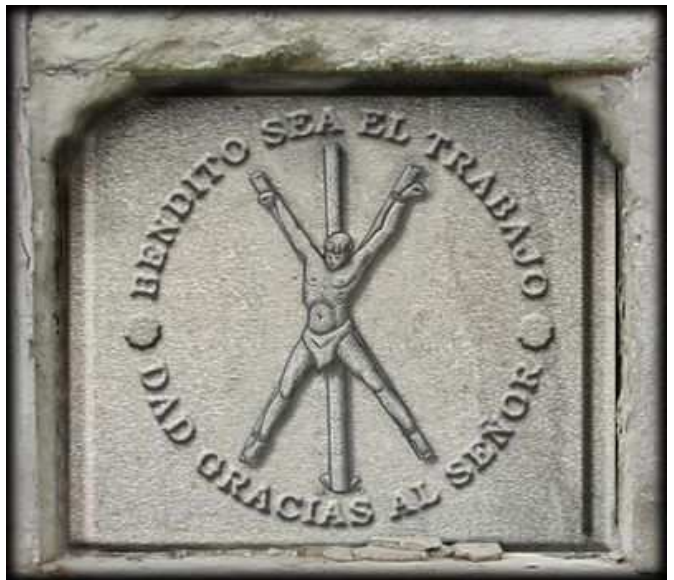

Figura 2. 250 × 250 -//www.clickgratis.com.br//tripalium.jpg Fonte: Imagens de tripalium (2013)

É possível que muito do sentimento e da maneira que nós vemos o trabalho, ou, que muitos dos problemas relacionados aos sujeitos dentro das organizações estejam sustentados nesse imaginário coletivo de trabalho, construído e transformado por muitos. 
Do trabalhador das fábricas exigia-se somente a compreensão da sua tarefa. Não havia informação sobre todo o processo da empresa, nem sobre a importância de cada tarefa e a sua relação com as demais. Com o passar do tempo, algumas destas questões vão se transformando e, hoje, sabemos da importância de cada trabalhador compreender a relação do seu trabalho com a de outros trabalhadores da mesma corporação. Investe-se em tornar claro o negócio da empresa para todos que ali trabalham, dentro de uma modelo de gestão que considere a necessidade da informação na ambiência laboral, o que em muitas corporações ainda está incrustado no que coloca Wolton (2006).

\footnotetext{
Quando a ordem social e política está diretamente ligada aos ciclos da natureza ou da hierarquia religiosa ou militar, há trocas, mas cada coisa e cada um permanecem em seu lugar. A comunicação existe, mas segundo um esquema vertical, o da ordem estabelecida. (WOLTON, 2006, p.26).
}

Atualmente, algumas empresas adotam programas modernos de gestão, desenvolvem pesquisas de satisfação com os empregados e procuram melhorar a comunicação interna e o clima corporativo. Este cenário do mundo corporativo sinaliza mudanças efetivas no imaginário relacionado ao trabalho e à cultura das organizações no contexto hodierno.

\subsection{O imaginário e a cultura das organizações}

As mediações sociais e o cotidiano estão investidos de cultura e formas peculiares de ser e ter com o mundo. Para Freitas (2002), “a cultura organizacional é o principal meio de construção, suporte e veiculação do imaginário desenvolvido pelas empresas" (FREITAS, 2002, p. 12). Assim, deve ser utilitária, adaptativa e funcionalmente integrada, pois Marchiori (2008) acredita que a cultura impõe significado para o universo, possibilitando seu entendimento.

Tanto o imaginário como a cultura são mutáveis. O imaginário de um sujeito interfere no imaginário coletivo, que por sua vez, reconstrói o imaginário do sujeito, em uma relação dialética. E isso ocorre na sociedade e nas organizações, já que estas refletem o meio em que estão insertas e também o constroem.

Alguns autores esclarecem mais esta relação. Mafessoli (2001) ressalta que cada pessoa pode interpretar o imaginário coletivo da sua maneira, mas, 
normalmente, o imaginário é muito pouco individual, haja vista que é algo comunitário e partilhado (MAFESSOLI, 2001a, p. 80 apud RAHDE, 2008, p. 103).

Castoriadis (1981) amplia essa relação do coletivo com o individual ao asseverar que

somos todos, em primeiro lugar, fragmentos ambulantes da instituição de nossa sociedade - fragmentos complementares, suas "partes totais", como diria um matemático. A instituição produz indivíduos conforme suas normas, e estes indivíduos, dada sua construção, não apenas são capazes de, mas obrigados a, reproduzir a instituição. (CASTORIADIS, 1981, p. 230).

A cultura e a identidade das organizações estão imbricadas à cultura e à identidade dos indivíduos que ali trabalham. Estão, também, totalmente relacionadas com a cultura e com a identidade do espaço geográfico em que estão inseridas, pois a cultura é "um sistema de concepções expressas herdadas em formas simbólicas por meio das quais o homem comunica, perpetua e desenvolve seu conhecimento sobre as atitudes para a vida". (GEERTZ, 2001 apud MARCHIORI, 2008, p.70).

À luz dos conhecimentos compartilhados por outros estudiosos da cultura organizacional, compreendemos que a cultura de uma organização pode ser expressa através de vários elementos como: os artefatos visíveis (a arquitetura da estrutura física, o modelo de disposição de móveis, o desenho do organograma, o uso constante de siglas, o vestuário utilizado), os valores que governam o comportamento das pessoas e a maneira como as pessoas pensam, sentem e percebem o seu local de trabalho.

O estudo da cultura organizacional pode ser feito a partir da adoção de muitos métodos, como por meio dos elementos acima citados, mas também, no seio deo de uma perspectiva histórica e antropológica. Conhecer a memória organizacional, seja através de documentos ou de relatos dos empregados, é um dos instrumentos de estudo da cultura de uma organização.

Maricato (2006) aclara mais sobre a importância de se conhecer as pessoas que trabalharam em determinada organização e a história que envolve a relação entre elas no ambiente de trabalho.

Se uma empresa é feita por pessoas, uma quantidade enorme de vivências, fracassos e sucessos, tentativa e erros, recuos e inovações, coragem e determinação, permeia a história conjunta dos pioneiros e dos seus seguidores. (...) Só o autoconhecimento promoverá o entendimento de suas origens e a sinalização dos caminhos para o futuro, mas principalmente, irá 
Consideramos que os profissionais de comunicação precisam se envolver diretamente com o processo de investigação e produção de conhecimento no que tange à cultura organizacional e, cada vez mais, envidar esforços para a melhoria do relacionamento entre as pessoas que ali trabalham e entre a organização e todos os outros segmentos de público com os quais se relaciona, haja vista que, na esteira de Bueno (2013), "a comunicação empresarial funciona como um espelho, que reflete culturas e tendências" (BUENO, 2013, p. 1).

Maricato (2006) ainda assevera que a comunicação organizacional deve se envolver no processo de conhecer o passado para fortalecer ou mudar o futuro das organizações.

Surge o desafio para a comunicação empresarial de, além do resgate e da manutenção da história vivida - o que chamamos de memória - liderar o pensamento do presente, como construção do futuro. Ou seja, quando estamos tratando das ações cotidianas e estratégicas do hoje, estamos construindo o que queremos ver o futuro, em concreto. (MARICATO, 2006, p. 129).

Este é um dos desafios que interpelam as organizações em um cenário de competitividade que as leva a um "vale tudo" no que se refere às metas de produção e de produtividade, aos relacionamentos com as redes de concorrência, à publicidade agressiva e estratagemas utilizados para amortecer o impacto de certos posicionamentos de mercado, o que cremos estar ligado à cultura e ao sistema de gestão das empresas.

\subsection{Cultura nacional, imaginário e estilos de gestão}

Os estilos de gestão nas organizações, seja do presidente ao supervisor ou encarregado, são formados tanto pela cultura organizacional, quanto pela cultura nacional. Alguns autores se dedicaram ao tema e produziram algumas reflexões sobre a gerência e a autoridade nas empresas brasileiras. Tais estudos elencam alguns estilos de gestão, que foram construídos com base em imagens, personagens e mitos da história brasileira.

Motta (1995) afirma que "bastante diversa é a situação da cultura brasileira. O fantasma do corpo escravo no discurso do brasileiro é algo muito forte e não pode de nenhuma forma ser um simples efeito do passado escravocrata" (MOTTA, 1995, p. 
191- 192), influenciando nas concepções e modelos de administração que ainda perduram no seio das organizações, sobretudo naquelas que são essencialmente brasileiras.

Machado (2008) pesquisou alguns modelos gerenciais e por conta de seus estudos, comenta que:

esse modelo patriarcal sustenta hierarquias do tipo piramidal, de disciplina rígida, geradora de docilidade e sujeição. Foi esse modelo, concebido segundo o molde familiar, que chegou ao sistema empresarial brasileiro. Do pai-patrão esperam-se práticas como concessão de moradia, assistência médico-hospitalar, empréstimos, auxílios, gratificações. (MACHADO, 2008, p.46-47).

A partir das pesquisas de Machado, podemos considerar que talvez um dos estilos gerenciais mais comentados ou percebidos seja o estilo do coronel. A autora esclarece que:

\begin{abstract}
um segundo tipo de "gerente" brasileiro, muito presente na literatura, é o coronel. Ele apareceu quando as antigas províncias brasileiras se tornaram estados. Dominou a Primeira República ou República Velha. Naqueles anos, predominava a política dos governadores, baseada em acordos entre 0 governo federal e os estados, troca de favores e apoios recíprocos. 0 governo federal se sustentava nos arranjos com os estaduais e esses com os municipais. Nesse contexto, surgiu o coronelismo: o coronel era o chefe político local do município, da vila ou do distrito. Normalmente era um fazendeiro, frequentemente exportador. Como proprietário de grandes terras, seus agregados e dependentes formavam as milícias locais. (MACHADO, 2008, p. 47).
\end{abstract}

Dentro desse modelo, as relações entre os gestores e seus empregados são normalmente baseadas em autoritarismo, favoritismo, vigilância e punição. Para Bueno (2012), há empresas que não permitem o pensamento divergente e consideram que o "funcionário não foi contratado para dar opinião, mas para seguir as ordens do chefe" (BUENO, 2012). O autor complementa ainda que:

\begin{abstract}
as empresas continuam, em sua maioria, praticando a tese "de quem pode manda e quem tem juízo obedece", sufocando a liberdade de expressão, punindo aqueles que ousam expressar suas divergências e literalmente expulsando dos seus quadros centenas de jovens talentosos que não se curvam à truculência de chefias incompetentes. (BUENO, 2012, S/P).
\end{abstract}

Todas estas posturas apresentadas lembram a imagem do coronel investigada por Machado (2008) que acredita que ainda existe com característica paternalista e autoritária e é um óbice cultural para o desenvolvimento das organizações

existe ainda no país a figura do coronel empresarial no centro de cartéis e oligopólios, convivendo lado a lado a ilhas de perfeita racionalidade. Seu 
Vasconcellos (1995) também assevera a posição de Machado ao afirmar que "o imaginário do coronel continua presente no curral eleitoral, no voto de cabresto, na corrupção eleitoral, no clientelismo, no nepotismo, na apropriação do Estado por famílias importantes" (VASCONCELLOS, 1995, p. 227), estando arraigado à cultura brasileira e das organizações.

Este imaginário ainda está presente nas organizações e tem impactos importantes nas relações pessoais e de trabalho. Ele pode também contribuir com a formação da identidade profissional de cada trabalhador, gerado por meio de uma série de eufemismos empresariais que mais servem para sufocar a subjetividade do sujeito que inseri-lo de modo crítico na filosofia e práticas organizacionais.

\title{
2.4 Gestão: vigilância, controle e punição - o panoptismo ${ }^{5}$
}

Ainda dentro dos estudos que tratam do imaginário relacionado à figura do gestor nas organizações, Pinto (2008) faz uma reflexão importante sobre essas temáticas.

\begin{abstract}
Num ambiente como o das organizações, que vem sendo dominado cada vez mais pela ideia de gestão - e gestão talvez seja só outro nome mais açucarado para panóptico e para vigilância -, existe a ilusão de que se possui a forma de bem conduzir as coisas, de maneira que as coisas atinjam seus objetivos. (PINTO, 2008, p. 86).
\end{abstract}

Há evidências de que o panóptico foi muito utilizado em manicômios e em presídios, mas, sua utilização chegou às fábricas, durante a revolução industrial.

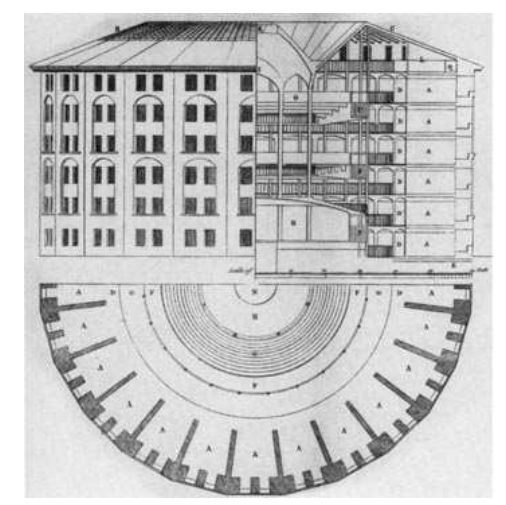

Figura 3: Panóptico, por Jeremy Bentham ( $350 \times 360$ pixels, tam 32 kB, tipo MIME: image/jpeg) Fonte: Panóptico (2013)

\footnotetext{
${ }^{5}$ Panóptico (Figura 3) foi o nome dado a um centro penitenciário, desenhado pelo filósofo e jurista inglês Jeremy Bentham no Século XVIII.
} 
O filme "Tempos Modernos" (Figura 4) de Charles Chaplin mostra uma espécie de panóptico utilizado pelo presidente de uma empresa que controla a velocidade da linha de montagem e a atuação dos operários na fábrica. No filme, Chaplin ironiza o controle excessivo no ambiente de trabalho, mostrando a cena em que é repreendido pelo presidente quando está no banheiro, em um intervalo de trabalho.

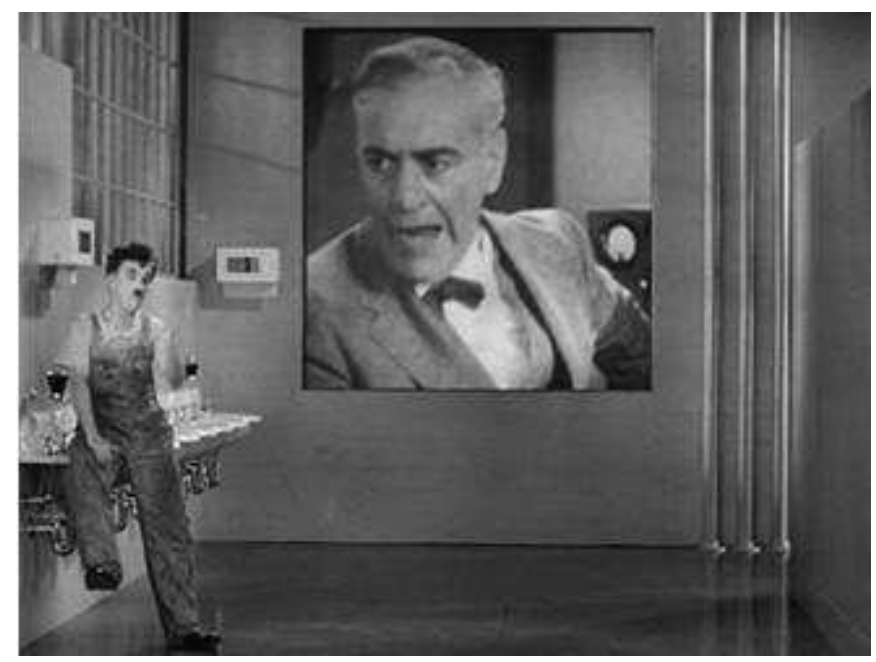

Figura 4: Cena do Filme Tempos Modernos de Charles Chaplin.

Fonte: Charles Chaplin (2013)

Foucault (1987), na obra "Vigiar e Punir" coloca em discussão o uso do panóptico, acreditando que ele pode constituir-se em aparelho para controlar seus mecanismos intrínsecos.

Em sua torre de controle, o diretor pode espionar todos os empregados que tem a seu serviço: enfermeiros, médicos, contramestres, professores, guardas; poderá julgá-los continuamente, modificar seu comportamento, impor-lhes métodos que considerar melhores; e ele mesmo, por sua vez, poderá ser facilmente observado. (FOUCAULT, 1987, p. 169).

O autor esclarece ainda, que os tipos de controle e vigilância promovidos com o uso do panóptico estão em diferentes mediações sociais, abrangendo a escola, a oficina e o exército, funcionando como espaços de repressão:

[...] toda uma micropenalidade do tempo (atrasos, ausências, interrupções das tarefas), da atividade (desatenção, negligência, falta de zelo), da maneira de ser (grosseria, desobediência), dos discursos (tagarelice, insolência), do corpo (atitudes 'incorretas', gestos não conformes, sujeira), da sexualidade (imodéstia, indecência). Ao mesmo tempo é utilizada, a título de punição, toda uma série de processos sutis, que vão do castigo físico leve a privações ligeiras e a pequenas humilhações. (FOUCAULT, 1987, p. 149). 
Importante sabermos e verificarmos os efeitos deste sistema de vigilância no imaginário e na consciência do sujeito. Sobre isso, Foucault (1987) declara que o mais relevante efeito do panóptico está na indução do detento a um estado de consciência e perene visibilidade garantidora do "funcionamento automático do poder" (1987, p.166). Os efeitos da vigilância precisavam ser permanentes ainda que sem ações contínuas, haja vista que os sujeitos se veem em uma estrutura de poder da qual eles mesmos são portadores.

Podemos afirmar que a cultura da vigilância e do controle persiste nas organizações até os dias atuais. Talvez o panóptico esteja invisível, nos corredores, nas salas, nos auditórios, na comunicação visual, nas "romantizadas" identidades corporativas e dentro de cada gestor ou empregado. Freitas (2002) declara que:

Foi dito que a nova estrutura organizacional exerce um controle mais sutil. $\mathrm{O}$ que antes era visível e claro nas relações verticalizadas de autoridade, dá lugar a uma ênfase nos grupos, equipes e comitês formados por membros do mesmo nível, ou seja, mais horizontais. A aspereza da autoridade hierárquica se dilui na suavidade do controle que cada um toma para si. (FREITAS, 2002, p. 76).

Essas questões acendem um sinal de alerta nas organizações contemporâneas, que cada vez mais se valem de comportamentos e funcionários de visão selvagem, criados e construídos no ventre de uma sociedade de consumo na qual não há regras, senão a do sucesso, a do massageamento do ego do gestor, a do policiamento, da produtividade em tempo recorde e da desproporção entre o que se fala e o que se pratica, cavando um abismo entre ética e estética organizacional.

\subsection{Do Panóptico ao binóculo - o caso do Dr. Kirsti ${ }^{6}$ :}

Dr. Kirsti era diretor de uma conceituada empresa pública por volta da década de 1960, situada em uma grande fazenda no interior do país. Ele comandava cerca de 400 empregados, que diariamente desenvolviam funções bem diferenciadas. Alguns realizavam tarefas braçais, como capinar, limpar, tratar de animais e transportar cargas.

\footnotetext{
${ }^{6}$ Foi utilizado um nome fictício com o objetivo de aproveitar nossa experiência, sem expormos o personagem da história real.
} 
Ele era famoso por sua firmeza, rigidez, dedicação e pela curiosa e divulgada "mania" de controlar e vigiar os empregados com o uso de um binóculo. Da sua sala, no segundo andar do prédio principal da empresa, através de grandes janelas de vidro, Dr. Kirsti passava horas olhando por seu binóculo alguns campos de trabalho que estivessem visíveis às suas lentes. Ao perceber qualquer "irregularidade", o diretor acionava sua secretária que, de forma "urgentíssima", convocava o empregado para uma visita à sala da diretoria.

As reclamações do diretor eram sobre problemas diversos: a demora do empregado no intervalo do lanche, o uso inadequado de algum equipamento ou até mesmo o uso de bebida alcoólica durante o período do trabalho. Os empregados já estavam acostumados com a atitude do chefe e procuravam se comportar de forma "adequada" e aceitável para evitar as visitas "urgentíssimas" à sala do diretor.

Com o passar dos anos, Dr. Kirsti e muitos dos empregados se aposentaram, todavia outros que trabalhavam naquela época ainda permanecem na mesma empresa, que ganhou novo nome, nova missão e outro sistema de gestão.

Alguns funcionários contam casos diversos do diretor e só hoje puderam perceber uma questão: o binóculo do Dr. Kirsti não conseguia visualizar todas as áreas da fazenda. Então, como ele ficava sabendo de algumas coisas que aconteciam? Se ele não podia ver com o próprio binóculo, como se inteirava do ocorrido?

Alguns empregados, hoje, compreendem que os supervisores da época, com um estilo coronelista de gestão, delatavam os colegas para o diretor e tinham no binóculo um aliado para evitar problemas de comportamento, de produtividade e de posições contrárias aos status quo.

O binóculo do Dr. Kirsti está em exposição no memorial da organização. Os empregados comentam o caso e até acham o ocorrido jocoso. O fato é que o imaginário dessa vigilância constante, somada à desconfiança do supervisor ou do colega quanto à conduta de delatar, ainda fazem parte da cultura dessa organização, gerando alguns problemas gerenciais e de relacionamento entre os empregados.

Essa percepção nos mostra como certas formas de gerir se mantêm encalacradas no imaginário e no "inconsciente do coletivo da organização", servindo como forma de panóptico em plena sociedade contemporânea - vulga sociedade de liberdades - na qual deveria imperar o reconhecimento da importância do outro, 
aceitando nossa dependência em relação a ele; parafraseando Wolton (2006), aceitando esse outro e defendendo nossa identidade própria.

Esse caso corrobora a posição de Foucault (1987) quando tece considerações acerca do modus operandi do panóptico; em pleno século XXI, ainda encontramos situações nas quais há micropenalidades por conta do "mau" uso do tempo, do desempenho em atividades do mundo do trabalho e na forma de ser "persona" no contexto organizacional, investido de personalidades as mais diferentes possíveis. Concomitante a isso, ainda observamos nas empresas, uma série de processos sutis, que vão do castigo a privações rápidas e pequenas humilhações. Não é de se estranhar que isso aconteça nas organizações de hoje, pois uma das questões mais emergentes é a localização do elemento humano nas práticas selvagens do capitalismo neoliberal na sociedade de consumo. Afinal, quem dirige, pensa e toma decisões nas empresas são pessoas, não máquinas.

\section{Considerações finais}

Grande importância têm os estudos organizacionais que se aprofundam na comunicação, na cultura e no imaginário, sobretudo aqueles que almejam melhorias nos relacionamentos entre as pessoas no interior da sociedade e das corporações. Ao considerarmos as estruturas do panóptico desenhado por Foucault e trazermos à baila o "caso Dr. Kirsti", compreendemos que, muito embora as organizações se esmerem por construir modelos de gestão participativa, dialógica e aberta, convivemos ainda, com questões sérias de assédio sexual, moral, exploração, cerceamento do pensamento diverso e contrário, etc. Ou seja, há alguns panópticos contemporâneos ainda em funcionamento em certas empresas.

Acreditamos que as organizações compreenderam que é preciso transformar e construir um novo imaginário e uma nova cultura, e que sem a participação e o envolvimento dos empregados, não faz sentido investimento algum em tecnologia, produção e comunicação; quanto mais as máquinas evoluem, mais o empresariado precisa entender a necessidade de desenvolvimento de pessoal e retenção de capital humano, pois é fulcral que passem, como sugere Wolton (2006), por um exercício intelectual de verificação e crítica de preconceitos, estereótipos, representações e ideologias que podem ser obstáculos para a gestão empresarial e principalmente para a comunicação. 
A cultura de vigiar, controlar e punir, só permanecerá se os atores envolvidos nesse processo de sequestro da subjetividade do outro, não estiverem dispostos a mudar e adequar-se aos novos cenários que se nos apresentam. Os panópticos e os binóculos precisam ser reconstruídos no imaginário coletivo e execrados do sistema organizacional. Nesse rendilhado de noções, problemas e antinomias, certas palavras passam a ser essenciais e repensadas: identidade, alteridade, redes, diáspora, gestão, liberdade e participação. Onde, quando e como se inserem nos contextos corporativos? Onde está o outro tão conclamado na comunicação institucional e mercadológica senão apagado em sua subjetividade e "assassinado" em suas posições e pensar?

Ao assumir as mudanças nos processos comunicacionais, as organizações precisam enfrentar o desafio do diálogo para que todos possam ser agentes transformadores da cultura e da sociedade, e as empresas possam levar a efeito sua missão nesse mundo globalizado, midiatizado e mediatizado. Nesse sentido, destaquemos que no seio das organizações, as profissões de comunicação ganham um lugar basilar. De acordo com Wolton (2006), sua ascensão não significa um pouco de óleo nas engrenagens, mais plumas e paetês; é, senão, uma necessidade absoluta que traduz mudanças sociais profundas nos paradigmas de gestão e administração.

Dr. Kirsti provavelmente ficou no universo estético corporativo e da incomunicação. O olhar e as transformações de hoje estão no equilíbrio entre a ética e a estética e no sentimento insuportável de situações sociais em que a autonomia do indivíduo é negada e sufocada. Que a máxima de Francis Bacon "sapatos de chumbo nos pés dos homens, nunca asas em suas costas", seja uma verdade do passado, uma verdade do Dr. Kirsti: o mundo, as pessoas e as organizações precisam da leveza, bons costumes, moral, partilha e comunicação; esta em seu sentido mais imanente. 


\section{Referências}

BALDISSERA, Rudimar. Organizações como complexus de diálogos, subjetividades e significação. In: KUNSCH, Margarida Maria Krohling (Org.). A comunicação como fator de humanização das organizações. São Caetano do Sul: Difusão, 2010. p. 61-76.

BATISTTI, Roselaine Bencke; BAVARESCO, Angela Maria. Estudo bibliográfico sobre aspectos geradores de estresse que afetam o ser humano no ambiente de trabalho. Unoesc \& Ciência - ACHS, Joaçaba, v. 1, n. 2, p. 139-148, jul./dez. 2010.

BUENO, Wilson da Costa. A comunicação como espelho das culturas empresariais. Disponível em: http://seer.uscs.edu.br/index.php/revista_comunicacao_inovacao/article/view/822>. Acesso em: 19 fev. 2013.

. Comunicação empresarial: transparência ou maquiagem? 2012. Disponível em:

<http://interfacecomunicacao.com.br/blog/sem-categoria/comunicacao-empresarial-transparencia-oumaquiagem>. Acesso em: 20 fev. 2013.

CASTORIADIS, Cornelius. As encruzilhadas do labirinto II: os domínios do homem. Tradução: José Oscar de Almeida Marques. Rio de Janeiro: Paz e Terra, 1981. (Coleção Rumos da Cultura Moderna, v. 54). CHARLES Chaplin. 1 fotografia, p\&b. Cena do filme "Tempos Modernos". Disponível em: <http://org2.wikispaces.com/file/view/taylor_3.jpg/148441539/taylor_3.jpg>. Acesso em: 18 fev. 2013. CURVELLO, João José Azevedo. Comunicação interna e cultura organizacional. São Paulo: Scorecci, 2002.

DICIONÁRIO do Aurélio on line. Disponível em: <http://74.86.137.64-static.reverse.softlayer.com>. Acesso em: 20 jul. 2012.

FOUCAULT, Michael. Vigiar e punir: nascimento da prisão. Tradução de Raquel Ramalhete. 29. ed. Petrópolis: Vozes, 1987.

FREITAS, Maria Ester de. Cultura organizacional: identidade, sedução e carisma? 3. ed. Rio de Janeiro: FGV, 2002.

IMAGENS de tripalium. 2 fotografias, p\&b. Disponível em: < http://www.clickgratis.com.br/fotosimagens/tripalium>. Acesso em: 18 fev. 2013. (Figuras 1 e 2)

MACHADO, Marília Novais da Mata. Cultura e imaginário organizacionais: análise psicossociologia de algumas imagens típicas brasileiras. Pesquisas e Práticas Psicossociais, São João Del Rei, v. 3, n. 1, p. 4450, ago. 2008.

MARCHIORI, Marlene. Cultura e Comunicação Organizacional: um olhar estratégico sobre a organização. 2a Ed. São Caetano do Sul: Ed. Difusão, 2008.

MARICATO, Adriano. História e memória. In: MARCHIORI, Marlene. Faces da cultura e da comunicação organizacional. São Caetano do Sul: Difusão, 2006. p. 123-133.

MOTTA, Fernando C. Prestes. Cultura nacional e cultura organizacional. In: DAVEL, E. P. B.;

VASCONCELLOS, J. G. M. de (Org.). Recursos Humanos e subjetividade. Petrópolis: Vozes, 1995. p. 187197.

PANÓPTICO. 1 fotografia, p\&b. Disponível 
em:<http://www.vitruvius.com.br/media/images/magazines/grid_9/5330ffb343b0_panopticon.jpg>. Acesso em: 18 fev. 2013.

PINTO, Julio. Comunicação organizacional ou comunicação no contexto das organizações? In: OLIVEIRA, Ivone de Lourdes; SOARES, Ana Thereza Nogueira. Interfaces e tendências da comunicação no contexto das organizações. São Caetano do Sul: Difusão, 2008. p. 81-89.

RAHDE, Maria Beatriz Furtado. Comunicação e imaginário os contos do cinema contemporâneo: uma estética em transição. Comunicação, Mídia e Consumo, São Paulo, v. 5, n. 12, p. 97-112, mar. 2008. VASCONCELLOS, João Gualberto Moreira. O coronelismo nas organizações: a gênese da gerência autoritária brasileira. In: DAVEL, E. P. B.; VASCONCELLOS, J. G. M. de (Org.). Recursos humanos e subjetividade. Petrópolis: Vozes, 1995. p. 220-231.

WOLTON, Dominique. É preciso salvar a comunicação. São Paulo: Paulus, 2006. 